\title{
Two Ecotypes Mutual Grafting Improves Photosynthesis of Post Generations of Solanum photeinocarpum under Cadmium Stress
}

\author{
Zicheng Lu, ${ }^{1, a}$, Jianhua Li, ${ }^{2, b}$, Huan Yao ${ }^{3, c}$, Qian Zhang ${ }^{3, d}$, Maolin Chen ${ }^{4, e}$, \\ Mei Qing ${ }^{3, f}$ and Lijin Lin ${ }^{5, g *}$ \\ ${ }^{1}$ College of Agronomy, Sichuan Agricultural University, Chengdu, Sichuan, China \\ ${ }^{2}$ Sichuan Ya'an Municipal Product Quality Supervision \& Inspection Institute, Ya'an, Sichuan, China \\ ${ }^{3}$ College of Horticulture, Sichuan Agricultural University, Chengdu, Sichuan, China \\ ${ }^{4}$ College of Economics, Sichuan Agricultural University, Chengdu, Sichuan, China \\ ${ }^{5}$ Institute of Pomology and Olericulture, Sichuan Agricultural University, Chengdu, Sichuan, China \\ alzcheng666@qq.com, ${ }^{b}$ 710753781@qq.com, ${ }^{c}$ 272365026@qq.com, ${ }^{\text {d1964292607@qq.com, }}$ \\ 3208585092@qq.com, ${ }^{\mathrm{e}}$ 1115435013@qq.com, ${ }^{9}$ llj800924@163.com
}

${ }^{*}$ Corresponding author. Zicheng Lu and Jianhua Li contributed equally to this work.

Keywords: Solanum photeinocarpum; Mutual grafting; Photosynthesis; Post generation

Abstract: The effects of mutual grafting on the photosynthesis of two ecotypes of post generation Solanum photeinocarpum under cadmium $(\mathrm{Cd})$ stress were studied by the pot experiment, and the photosynthetic pigment contents, photosynthetic characteristics and soluble sugar contents in post generations of $S$. photeinocarpum were determined. Under $\mathrm{Cd}$ stress, two ecotypes of $S$. photeinocarpum mutual grafting improves the chlorophyll $a$, chlorophyll $b$, total chlorophyll and carotenoid contents of their post generations. The mutual grafting increased the net photosynthetic rate $(\mathrm{Pn})$, transpiration rate $(\mathrm{Tr})$, stomatal conductance $(\mathrm{Gs}), \mathrm{CO}_{2}$ concentration of intercellular $(\mathrm{Ci})$ of post generations of $S$. photeinocarpum, and decreased the value of pressure deficit leaf (Vpdl) of that compared with the un-grafted control, respectively. Compared with the un-grafted control, the grafting increased the soluble sugar contents in roots, stems, leaves and shoots of post generations of $S$. photeinocarpum. Therefore, two ecotypes mutual grafting could improve the photosynthesis of post generations of $S$. photeinocarpum under cadmium stress.

\section{Introduction}

Solanum photeinocarpum is a potential cadmium (Cd) hyperaccumulator plant [1]. Compared with the farmland ecotype, the mining ecotype of S. photeinocarpum was short and lower biomass, but had more Cd contents in plant [2]. Compared with the other Cd-hyperaccumulator plants [3-4], the phytoremediation ability of $S$. photeinocarpum is low. So, to further enhancing the phytoremediation ability of $S$. photeinocarpum, a pot experiment was conducted to study the effects of mutual grafting on the photosynthesis of two ecotypes of post generations $S$. photeinocarpum under Cd stress. The objectives of this study were to determine whether mutual grafting could enhance photosynthetic ability of two ecotypes of post generations $S$. photeinocarpum under $\mathrm{Cd}$ stress, and provide a reference for other hyperaccumulator plants.

\section{Materials and Methods}

Materials. The seeds of two ecotypes (mining ecotype and farmland ecotype) of S. photeinocarpum were collected from Tangjiashan lead-zinc mine and farmland of Ya'an campus farm of Sichuan Agricultural University in May, 2016, air-dried and stored at $4{ }^{\circ} \mathrm{C}$ respectively. The Tangjiashan lead-zinc mine $\left(29^{\circ} 24^{\prime} \mathrm{N}, 102^{\circ} 38^{\prime} \mathrm{E}\right)$ locates in Hanyuan County, Sichuan Province, China, with an typical dry-hot valley climate. The farm of Sichuan Agricultural University (29 $\left.59^{\prime} \mathrm{N}, 102^{\circ} 59^{\prime} \mathrm{E}\right)$ locates in Yucheng County, Sichuan Province, China, with an humid subtropical monsoon climate. 
Grafting. The seeds of two ecotypes of S. photeinocarpum were sown in the farmland of the Chengdu campus in June, 2016. When the $S$. photeinocarpum seedlings reached a height of $\sim 10 \mathrm{~cm}$ (eight expanded euphyllas, rapid growth stage), the grafting was conducted. The grafting method was cleft grafting bound with 1-cm-wide plastic film. All of the leaves of the rootstocks remained. There were four treatments in the experiment. (1) Un-grafted of farmland ecotype (FCK). (2) Un-grafted of mining ecotype (MCK). (3) The farmland ecotype as scion grafted on the rootstocks of mining ecotype (FSC). (4) The mining ecotype as scion grafted on the rootstocks of farmland ecotype (MSC). When the grafting was completed, the soil moisture content was maintained at $80 \%$ of field capacity, and all of the seedlings were covered with transparent plastic film and a shade net. After $10 \mathrm{~d}$, the transparent plastic film, the shade net and the plastic binding films were removed. At maturity $(50 \mathrm{~d}$ after grafting), fruits of $S$. photeinocarpum from CK, scion and rootstock were collected, and the seeds were taken out from fruits, air-dried and stored separately at $4{ }^{\circ} \mathrm{C}$, which were recorded as un-grafted of farmland ecotype (FCK1), rootstock of farmland ecotype (FRT1), scion of farmland ecotype (FSC1), un-grafted of mining ecotype (MCK1), rootstock of mining ecotype (MRT1) and scion of mining ecotype (MSC1).

Experimental Design. The experiment was conducted at the Chengdu campus from April to July 2017. The soil samples were air-dried and passed through a 5-mm mesh in April 2017, and then $3.0 \mathrm{~kg}$ of soil was weighed into each polyethylene pot (15 cm tall, $18 \mathrm{~cm}$ diameter). Cd was added to make a final soil Cd concentration of $10 \mathrm{mg} / \mathrm{kg}$ [5] with a saturated heavy metal solution in the form of $\mathrm{CdCl}_{2} \cdot 2.5 \mathrm{H}_{2} \mathrm{O}$. The soils were mixed immediately and again after 8 weeks, during which soil moisture was kept at $80 \%$. The seeds of $S$. photeinocarpum were sown in the un-contaminated soil in May 2017. Four uniform S. photeinocarpum seedlings with four expanded true leaves of each treatment were transplanted into each pot in June 2017. Each treatment was repeated three times with the $10-\mathrm{cm}$ spacing between pots. The soil moisture content was maintained at $80 \%$ of field capacity until the plants were harvested. After $S$. photeinocarpum matured (30 d of cultivation at the fully blooming stage), the photosynthesis of each plant was determined by using LI-6400 portable photosynthesis meter (LI-COR Inc., USA). The photosynthetic parameters of the photosynthesis meter were manual control $\mathrm{CO}_{2}$ concentration $400 \mu \mathrm{mol} / \mathrm{mol}$, temperature $30^{\circ} \mathrm{C}$, light intensity 1000 $\mu \mathrm{mol} / \mathrm{m}^{2} / \mathrm{s}$. The determination of photosynthetic parameters were net photosynthetic rate $(\mathrm{Pn})$, transpiration rate $(\mathrm{Tr})$, stomatal conductance $(\mathrm{Gs}), \mathrm{CO}_{2}$ concentration of intercellular $(\mathrm{Ci})$ and value of pressure deficit leaf ( $\mathrm{Vpdl})$, and each treatment was repeated three times. After that, the upper mature leaves of plants were collected to determine the photosynthetic pigment (chlorophyll $a$, chlorophyll $b$, total chlorophyll and carotenoid) contents [6]. Then, the whole plants were then gently removed, the roots, stems and leaves were washed with tap water followed by deionized water, and dried at $80^{\circ} \mathrm{C}$ to constant weight. The soluble sugar contents in shoots of $S$. media were determined by anthrone colorimetry with dry weight plant samples [6].

Statistical Analyses. Statistical analyses were conducted using SPSS 13.0 statistical software (IBM, Chicago, IL, USA). Data were analyzed by one-way analysis of variance with least significant difference (LSD) at the $\mathrm{p}=0.05$ confidence level.

\section{Results and Discussion}

Photosynthetic Pigment Content in Post Generations of S. photeinocarpum. The chlorophyll $a$, chlorophyll $b$, total chlorophyll and carotenoid contents of farmland ecotype of $S$. photeinocarpum were higher than the mining ecotype (Table 1). Compared with FCK1, the chlorophyll $a$, chlorophyll $b$, total chlorophyll and carotenoid contents of FRT1 and FSC1 increased. FRT1 and FSC1 increased the total chlorophyll content by $13.54 \%(p<0.05)$ and $34.06 \%(p<0.05)$, respectively, compared with FCK1, and increased carotenoid content by $22.64 \%(p<0.05)$ and $42.77 \%(p<0.05)$, respectively. Compared with MCK1, the chlorophyll $a$, chlorophyll $b$, total chlorophyll and carotenoid contents of MRT1 and MSC1 increased. MRT1 and MSC1 increased the total chlorophyll content by $24.68 \%(p<0.05)$ and $16.00 \%(p<0.05)$, respectively, compared with MCK1, and 
increased carotenoid content by $33.55 \%(p<0.05)$ and $18.60 \%(p<0.05)$, respectively. The order of chlorophyll a/b was FCK1 > FRT1 > MCK1 > MSC1 > FSC1 > MRT1.

Table 1 Photosynthetic pigment content in post generations of S. photeinocarpum

\begin{tabular}{|c|l|l|l|c|c|}
\hline Treatments & $\begin{array}{c}\text { Chlorophyll } a \\
(\mathrm{mg} / \mathrm{g})\end{array}$ & $\begin{array}{c}\text { Chlorophyll } b \\
(\mathrm{mg} / \mathrm{g})\end{array}$ & $\begin{array}{c}\text { Total chlorophyll } \\
(\mathrm{mg} / \mathrm{g})\end{array}$ & $\begin{array}{c}\text { Chlorophyll } \\
\mathrm{a} / \mathrm{b}\end{array}$ & $\begin{array}{c}\text { Carotenoid } \\
(\mathrm{mg} / \mathrm{g})\end{array}$ \\
\hline FCK1 & $0.851 \pm 0.036 \mathrm{c}$ & $0.294 \pm 0.005 \mathrm{c}$ & $1.145 \pm 0.041 \mathrm{c}$ & 2.895 & $0.318 \pm 0.015 \mathrm{~d}$ \\
\hline FRT1 & $0.963 \pm 0.044 \mathrm{~b}$ & $0.337 \pm 0.023 \mathrm{bc}$ & $1.300 \pm 0.066 \mathrm{~b}$ & 2.858 & $0.390 \pm 0.017 \mathrm{bc}$ \\
\hline FSC1 & $1.069 \pm 0.037 \mathrm{a}$ & $0.466 \pm 0.017 \mathrm{a}$ & $1.535 \pm 0.054 \mathrm{a}$ & 2.294 & $0.454 \pm 0.018 \mathrm{a}$ \\
\hline MCK1 & $0.699 \pm 0.029 \mathrm{~d}$ & $0.245 \pm 0.016 \mathrm{~d}$ & $0.944 \pm 0.013 \mathrm{~d}$ & 2.853 & $0.301 \pm 0.014 \mathrm{~d}$ \\
\hline MRT1 & $0.809 \pm 0.039 \mathrm{c}$ & $0.368 \pm 0.031 \mathrm{~b}$ & $1.177 \pm 0.070 \mathrm{bc}$ & 2.198 & $0.402 \pm 0.012 \mathrm{~b}$ \\
\hline MSC1 & $0.791 \pm 0.055 \mathrm{~cd}$ & $0.304 \pm 0.017 \mathrm{c}$ & $1.095 \pm 0.038 \mathrm{c}$ & 2.602 & $0.357 \pm 0.017 \mathrm{c}$ \\
\hline
\end{tabular}

Values are means \pm standard errors. Means with the same letter within each column are not significantly different at $p<0.05$.

Photosynthetic Characteristics of Post Generations of S. photeinocarpum. Compared with the un-grafted control, the grafting improved the photosynthesis of post generations of $S$. photeinocarpum under $\mathrm{Cd}$ stress (Table 2). The grafting increased the $\mathrm{Pn}, \mathrm{Gs}, \mathrm{Ci}$, $\mathrm{Tr}$ of post generations of $S$. photeinocarpum, and decreased the Vpdl of that compared with the un-grafted control, respectively. Compared with FCK1, FRT1 and FSC1 increased Pn by $4.66 \%(p>0.05)$ and $41.83 \%(p<0.05)$, respectively, increased Gs by $22.85 \%(p<0.05)$ and $46.33 \%(p<0.05)$, respectively, increased $\mathrm{Ci}$ by $5.86 \%(p>0.05)$ and $15.62 \%(p<0.05)$, respectively, and increased $\mathrm{Tr}$ by $7.42 \%(p>0.05)$ and $32.54 \%(p<0.05)$, respectively. Compared with MCK1, MRT1 and MSC1 increased Pn by $35.97 \%(p<0.05)$ and $10.36 \%(p<0.05)$, respectively, increased Gs by $58.92 \%(p<$ $0.05)$ and $19.57 \%(p<0.05)$, respectively, increased $\mathrm{Ci}$ by $15.37 \%(p<0.05)$ and $8.18 \%(p<0.05)$, respectively, and increased $\operatorname{Tr}$ by $56.74 \%(p<0.05)$ and $23.64 \%(p<0.05)$, respectively. FRT1 and FSC1 decreased Vpdl by 4.61\% ( $p>0.05)$ and 31.80\% ( $p<0.05)$, respectively, compared with FCK1, and MRT1 and MSC1 decreased Vpdl by 35.64\% $(p<0.05)$ and $25.96 \%(p<0.05)$, respectively, compared with MCK1.

Table 2 Photosynthetic characteristics of post generations of $S$. photeinocarpum

\begin{tabular}{|c|l|c|c|c|c|}
\hline Treatments & $\begin{array}{c}\mathrm{Pn} \\
\left(\mu \mathrm{mol} \mathrm{CO} / \mathrm{m}^{2} / \mathrm{s}\right)\end{array}$ & $\begin{array}{c}\mathrm{Gs} \\
\left(\mathrm{mol} \mathrm{H} \mathrm{H}_{2} / \mathrm{m}^{2} / \mathrm{s}\right)\end{array}$ & $\begin{array}{c}\mathrm{Ci} \\
(\mu \mathrm{mol} \mathrm{CO} / \mathrm{mol})\end{array}$ & $\begin{array}{c}\mathrm{Tr} \\
(\mathrm{mmol} \\
\left.\mathrm{H}_{2} \mathrm{O} / \mathrm{m}^{2} / \mathrm{s}\right)\end{array}$ & $\begin{array}{c}\text { Vpdl } \\
(\mathrm{kPa})\end{array}$ \\
\hline FCK1 & $29.81 \pm 1.01 \mathrm{~cd}$ & $0.477 \pm 0.016 \mathrm{~d}$ & $233.78 \pm 7.32 \mathrm{~d}$ & $4.18 \pm 0.23 \mathrm{c}$ & $2.17 \pm 0.10 \mathrm{a}$ \\
\hline FRT1 & $31.20 \pm 2.00 \mathrm{~cd}$ & $0.586 \pm 0.014 \mathrm{c}$ & $247.48 \pm 4.26 \mathrm{~cd}$ & $4.49 \pm 0.10 \mathrm{c}$ & $2.07 \pm 0.07 \mathrm{a}$ \\
\hline FSC1 & $42.28 \pm 2.34 \mathrm{a}$ & $0.698 \pm 0.019 \mathrm{~b}$ & $270.29 \pm 8.80 \mathrm{ab}$ & $5.54 \pm 0.39 \mathrm{~b}$ & $1.48 \pm 0.02 \mathrm{~b}$ \\
\hline MCK1 & $29.16 \pm 0.60 \mathrm{~d}$ & $0.465 \pm 0.018 \mathrm{~d}$ & $238.09 \pm 7.21 \mathrm{~d}$ & $4.23 \pm 0.29 \mathrm{c}$ & $2.08 \pm 0.05 \mathrm{a}$ \\
\hline MRT1 & $39.65 \pm 1.18 \mathrm{~b}$ & $0.739 \pm 0.026 \mathrm{a}$ & $274.68 \pm 7.42 \mathrm{a}$ & $6.63 \pm 0.32 \mathrm{a}$ & $1.32 \pm 0.04 \mathrm{c}$ \\
\hline MSC1 & $32.18 \pm 0.56 \mathrm{c}$ & $0.556 \pm 0.030 \mathrm{c}$ & $257.56 \pm 9.59 \mathrm{bc}$ & $5.23 \pm 0.13 \mathrm{~b}$ & $1.54 \pm 0.06 \mathrm{~b}$ \\
\hline
\end{tabular}

Values are means \pm standard errors. Means with the same letter within each column are not significantly different at $p<0.05$.

Soluble Sugar Content in Post Generations of S. photeinocarpum. Compared with the un-grafted control, the grafting increased the soluble sugar contents in roots, stems, leaves and shoots of post generations of S. photeinocarpum under Cd stress (Table 3). Compared with FCK1, FRT1 and FSC1 increased the soluble sugar content in roots by $17.13 \%(p<0.05)$ and $26.73 \%(p<0.05)$, respectively, increased the soluble sugar content in stems by $23.40 \%(p<0.05)$ and $39.72 \%(p<0.05)$, respectively, increased the soluble sugar content in leaves by $11.18 \%(p<0.05)$ and $20.66 \%(p<$ $0.05)$, respectively, and increased the soluble sugar content in shoots by $16.54 \%(p<0.05)$ and $28.75 \%(p<0.05)$, respectively. Compared with MCK1, MRT1 and MSC1 increased the soluble 
sugar content in roots by $51.50 \%(p<0.05)$ and $26.53 \%(p<0.05)$, respectively, increased the soluble sugar content in stems by $48.99 \%(p<0.05)$ and $14.69 \%(p>0.05)$, respectively, increased the soluble sugar content in leaves by $33.09 \%(p<0.05)$ and $14.27 \%(p<0.05)$, respectively, and increased the soluble sugar content in shoots by $39.04 \%(p<0.05)$ and $13.47 \%(p<0.05)$, respectively.

Table 3 Soluble sugar content in post generations of $S$. photeinocarpum

\begin{tabular}{|c|l|l|l|l|}
\hline Treatments & \multicolumn{1}{|c|}{$\begin{array}{c}\text { Roots } \\
(\mathrm{mg} / \mathrm{g})\end{array}$} & $\begin{array}{r}\text { Stems } \\
(\mathrm{mg} / \mathrm{g})\end{array}$ & $\begin{array}{r}\text { Leaves } \\
(\mathrm{mg} / \mathrm{g})\end{array}$ & $\begin{array}{c}\text { Shoots } \\
(\mathrm{mg} / \mathrm{g})\end{array}$ \\
\hline FCK1 & $58.03 \pm 3.15 \mathrm{~d}$ & $46.07 \pm 3.15 \mathrm{c}$ & $69.66 \pm 2.91 \mathrm{c}$ & $58.75 \pm 2.96 \mathrm{c}$ \\
\hline FRT1 & $67.97 \pm 3.82 \mathrm{bc}$ & $56.85 \pm 3.68 \mathrm{~b}$ & $77.45 \pm 1.13 \mathrm{~b}$ & $68.47 \pm 2.24 \mathrm{~b}$ \\
\hline FSC1 & $73.54 \pm 1.87 \mathrm{ab}$ & $64.37 \pm 1.70 \mathrm{a}$ & $84.05 \pm 2.38 \mathrm{a}$ & $75.64 \pm 2.04 \mathrm{a}$ \\
\hline MCK1 & $50.99 \pm 1.71 \mathrm{e}$ & $44.58 \pm 3.46 \mathrm{c}$ & $60.84 \pm 1.01 \mathrm{~d}$ & $53.23 \pm 1.08 \mathrm{~d}$ \\
\hline MRT1 & $77.25 \pm 2.78 \mathrm{a}$ & $66.42 \pm 0.62 \mathrm{a}$ & $80.97 \pm 3.70 \mathrm{ab}$ & $74.01 \pm 2.22 \mathrm{a}$ \\
\hline MSC1 & $64.52 \pm 2.91 \mathrm{~cd}$ & $51.13 \pm 1.26 \mathrm{bc}$ & $69.52 \pm 1.80 \mathrm{c}$ & $60.40 \pm 1.51 \mathrm{c}$ \\
\hline
\end{tabular}

Values are means \pm standard errors. Means with the same letter within each column are not significantly different at $p<0.05$.

\section{Conclusions}

Under Cd stress, two ecotypes of $S$. photeinocarpum mutual grafting improves the chlorophyll $a$, chlorophyll $b$, total chlorophyll and carotenoid contents of their post generations. The mutual grafting increased the Pn, Gs, Ci, Tr of post generations of S. photeinocarpum, and decreased the Vpdl of that compared with the un-grafted control, respectively. Compared with the un-grafted control, the grafting increased the soluble sugar contents in roots, stems, leaves and shoots of post generations of S. photeinocarpum. Therefore, two ecotypes mutual grafting could improve the photosynthesis of post generations of $S$. photeinocarpum under cadmium stress.

\section{Acknowledgements}

This work was financially supported by the 2016 Innovation Training Program of University Student (201610626032) and the Application Infrastructure Project of Science and Technology Department of Sichuan Province (2016JY0258).

\section{References}

[1] X.F. Zhang, H.P. Xia, Z.A. Li, P. Zhuang and B. Gao: Journal of Hazardous Materials Vol. 189 (2011), p. 414.

[2] J. Wang, L. Jin, L. Luo, M. Liao, X. Lv, Z. Wang, D. Liang and H. Xia: Environmental Monitoring and Assessment Vol. 188 (2016), p. 82.

[3] X.X. Long, Y.H. Wang and H.Y. Liu: Journal of Plant Ecology Vol. 32 (2008), p. 168.

[4] S.H. Wei, G. Clark, A.I. Doronila, J. Jin and A.C. Monsant: International Journal of Phytoremediation Vol. 15 (2013), p. 199.

[5] L. Lin, M. Liao, L. Mei, J. Cheng, J. Liu, L. Luo and Y. Liu: Environmental Progress \& Sustainable Energy Vol. 33 (2014), p. 1251.

[6] Z.B. Hao, J. Chang and Z. Xu: Plant Physiology Experiment (Harbin Institute of Technology Press, China 2004). 